Research Article

\title{
Rheological and Morphological Characterization of Styrene-Isoprene-Styrene (SIS) Modified Asphalt Binder
}

\author{
Mithil Mazumder, ${ }^{1}$ Anwar Siddique, ${ }^{1}$ Raju Ahmed, ${ }^{1}$ Soon-Jae Lee, ${ }^{1}$ and Moon-Sup Lee $\mathbb{I D}^{2}$ \\ ${ }^{1}$ Texas State University, San Marcos, TX 78666, USA \\ ${ }^{2}$ Korea Institute of Civil Engineering and Building Technology, Goyang, Republic of Korea \\ Correspondence should be addressed to Moon-Sup Lee; truepath@kict.re.kr
}

Received 19 June 2020; Revised 10 November 2020; Accepted 4 December 2020; Published 21 December 2020

Academic Editor: Bangbiao Wu

Copyright (c) 2020 Mithil Mazumder et al. This is an open access article distributed under the Creative Commons Attribution License, which permits unrestricted use, distribution, and reproduction in any medium, provided the original work is properly cited.

\begin{abstract}
The demand of strong polymer modified asphalt (PMA) binder is growing due to the increase of traffic and necessity to reduce the early deterioration of pavement due to cracking. In this study, physical and rheological properties of asphalt binder modified with a potential new polymer named styrene-isoprene-styrene (SIS) were investigated through the rotational viscometer (RV), the dynamic shear rheometer (DSR), and the bending beam rheometer (BBR). In order to have a depth understanding on the SIS binder at micro level, micro-morphological observations were conducted using optical microscopy, atomic force microscopy (AFM), environmental scanning electron microscopy (ESEM), and ellipsometry. The result of this study showed that (1) the addition of SIS modifiers increased the viscosity and had a positive effect on rutting resistance of the binder; (2) the addition of 5\%, $10 \%, 15 \%$, and $20 \%$ SIS content increased the rutting resistance by $600 \%, 3000 \%, 5600 \%$, and $6400 \%$, respectively; ( 3 ) the higher the SIS content, the better the cracking resistance of the binder and it is observed to have improved the stiffness by $26 \%$ and $51 \%$ with the addition of $5 \%$ and $10 \%$ content of SIS, respectively; (4) AFM images showed the significant correlation between the stiffness and microstructural properties of the binder; (5) the dominance of new oval phase over network structure was evident in ESEM images and observed to have significant correlation to the high stiffness of the binder; and (6) with the percentage increase of SIS modifier, the binder is found to have higher absorption at UV wavelength.
\end{abstract}

\section{Introduction}

Polymer modified asphalt (PMA) binders have gained interest in the second half of the twentieth century and now playing a vital role to limit the deterioration of road networks. As the asphalt pavement is getting exposed to higher traffic and unplanned overloading, it is necessary to investigate not only the rheological but also the microstructural properties of PMA binder in order to understand its chemistry at micro level. Several polymer modifications have been incorporated to increase the quality and performance of pavement such as polyethylene (PE), polypropylene (PP), ethylene-vinyl acetate (EVA), ethylene-butyl acrylate (EBA), and thermoplastic elastomers (e.g., styrene-butadiene-styrene (SBS), styrene-isoprene-styrene (SIS), and styreneethylene/butylene-styrene (SEBS)) [1-4]. Out of these polymers, SIS is a well-recognized thermoplastic elastomer because of its high stiffness and improved elastic response [5]. It has higher aging resistance, better asphalt-aggregate adhesivity, and good blend stability and improves elastic response, superior cohesion, tensile strength, and low temperature flexibility. A recent study by Ali et al. [6] compared the rheological properties among PG 64-22, SBS, crumb rubber modified (CRM), and SIS binder. The study showed that SIS binder has better performance compared to SBS binder in terms of viscosity, rutting, and cracking resistance.

The styrene-butadiene (SB) copolymer consists of linked blocks of polystyrene (PS) and polybutadiene (PB). According to Becker et al. [7], it is the most appropriate and used polymer for asphalt modification, followed by reclaimed tire rubber. Due to the formation of critical 
network between the binder and SBS, it increases the complex modulus and resulting increase in rutting resistance. SBS benefited the cracking resistance by reducing the rate of microdamage accumulation according to the Florida Department of Transportation (FDOT) and Federal Highway Administration (FHWA) $[8,9]$. However, the addition of SBS has some setbacks due to its economic and technical limits. It is able to increase the low temperature flexibility but some authors reported that a decrease in strength and resistance to penetration is observed at higher temperature [10].

On the other hand, SIS polymer has the potential to overcome the challenge of low temperature failure and cracking due to its high stiffness and elasticity [11]. SBS (styrene-b-butadiene-b-styrene) consists of butadiene as rubbery mid-block whereas SIS (styrene-b-isoprene-b-styrene) comprises isoprene as rubbery midblock. The SIS molecule chain is composed of isoprene. Due to its branch methyl in the isoprene group, it has better tenacity and compatibility with other materials $[5,12]$. Also, it increases the complex modulus at high temperature. The drawback of SIS polymer is its higher price compared to SBS polymer. However, due to its strong rheological characteristics and higher demand of durable pavement, it can be used in bridges or other heavy-duty structures. The study on SIS polymer is mostly limited to its individual characteristics. Also, the study on modification of bitumen using SIS is limited as well in terms of rheological and microstructural properties.

In order to build substantial knowledge, this study is to not only investigate the rheological performance of SIS modified binder at different contents but also characterize its micromorphology. For this purpose, control PG 64-22 is modified with five different percentages of SIS content $(0 \%$, $5 \%, 10 \%, 15 \%$, and $20 \%)$. Viscosity change as a function of SIS amount is evaluated through rotational viscometer (RV) test using two testing temperatures $\left(135^{\circ} \mathrm{C}\right.$ and $\left.180^{\circ} \mathrm{C}\right)$. Dynamic shear rheometer (DSR) and bending beam rheometer (BBR) were used to investigate high temperature and low temperature rheological behavior of asphalt binder modified with SIS at original state. Microstructural properties of SIS modified binder were investigated using optical microscopy, atomic force microscopy (AFM), and environmental scanning electron microscopy (ESEM). Also, absorption and reflection index of the binder is observed using ellipsometry. Figure 1 shows a flow chart of the experimental design used in this study.

\section{Experimental Design}

2.1. Materials. Performance grade (PG) 64-22 asphalt binder as a base binder was used in this study. The SIS modifier is a blend of linear SIS triblock and SI diblock copolymer. It contains approximately $18 \%$ SI diblock copolymer [13]. Figure 2 and Table 1 show the image and properties of SIS modifier.

2.2. Superpave Asphalt Binder Tests. The Superpave asphalt binder tests are used to measure the asphalt's performance at three stages of its life (original state, after mixing and construction, and after in-service aging). In this study, the selected test procedures included the viscosity test (AASHTO T 316), the dynamic shear rheometer (DSR) test (AASHTO T 315), and the bending beam rheometer (BBR) test.

An $8.5 \mathrm{~g}$ sample of the control binders and a $10.5 \mathrm{~g}$ sample of SIS binders were tested with a number 21 spindle and with a number 27 spindle in the Brookfield rotational viscometer at $135^{\circ} \mathrm{C}$ and at $180^{\circ} \mathrm{C}$. In the $\mathrm{DSR}$ test, the original binders were tested at a frequency of 10 radians per second which is equal to approximately $1.59 \mathrm{~Hz}$. Each asphalt binder at original state was used to determine the $\mathrm{G} *$ / $\sin \delta$ at $82^{\circ} \mathrm{C}$. Fatigue cracking property ( $\mathrm{G} * \sin \delta$ at intermediate temperature) was measured for unaged binders at $25^{\circ} \mathrm{C}$. The $\mathrm{BBR}$ test was conducted on asphalt beams $(125 \times 6.35 \times 12.7 \mathrm{~mm})$ at $-24^{\circ} \mathrm{C}$, and the creep stiffness $(S)$ of the binder was measured at a loading time of $60 \mathrm{~s}$. A constant load of $100 \mathrm{~g}$ was then applied to the beam of the binder, which was supported at both ends, and the deflection of center point was measured continuously. Testing was performed on aged samples.

2.3. Optical Microscopy. Hirox digital microscope (RH$2000 \mathrm{E}$ digital microscope) was used to observe the sample morphology. A binder sample of the mold specimen was prepared using different percentage of SIS modifier. Then, the sample surface was placed under the microscope at a magnification of 1500x (Figure 3).

2.4. Atomic Force Microscopy (AFM). A Model 840-002-380 Bruker Dimension Icon AFM (Bruker Instrument Inc.) is used to characterize the micromorphology of SIS binders through the surface images obtained on prepared sample. Topographical and phase images are captured. Figure 4 shows the AFM equipment.

AFM can be used to measure the forces between the tip and the sample as a function of their mutual separation. The AFM tapping mode imaging is performed on the binder samples to evaluate the morphology of the binder. In the tapping mode, the AFM tip is oscillated at its resonance frequency by a piezoelectric element connected to the tip holder assembly. The piezo-drive is adjusted using feedback control to maintain a constant tip-up-sample distance (set point) [14].

Both height and phase images are obtained with the scan rate of $0.99 \mathrm{~Hz}$ and the scan size of $20 \mu \mathrm{m} \times 20 \mu \mathrm{m}$. Height images represent the topography of the surface. Phase images are displayed for the unambiguous resolution which can be hindered by surface roughness in topographic image captured by the height mode in AFM. The colors in the phase images designate different mechanical properties of the phases, as obtained from sample-tip interactions, and could be related to their different viscoelastic properties or adhesion.

2.5. Environmental Electron Scanning Microscopy (ESEM). To image wet, soft, and non-conducting samples with scanning electrons, a technique called environmental SEM 


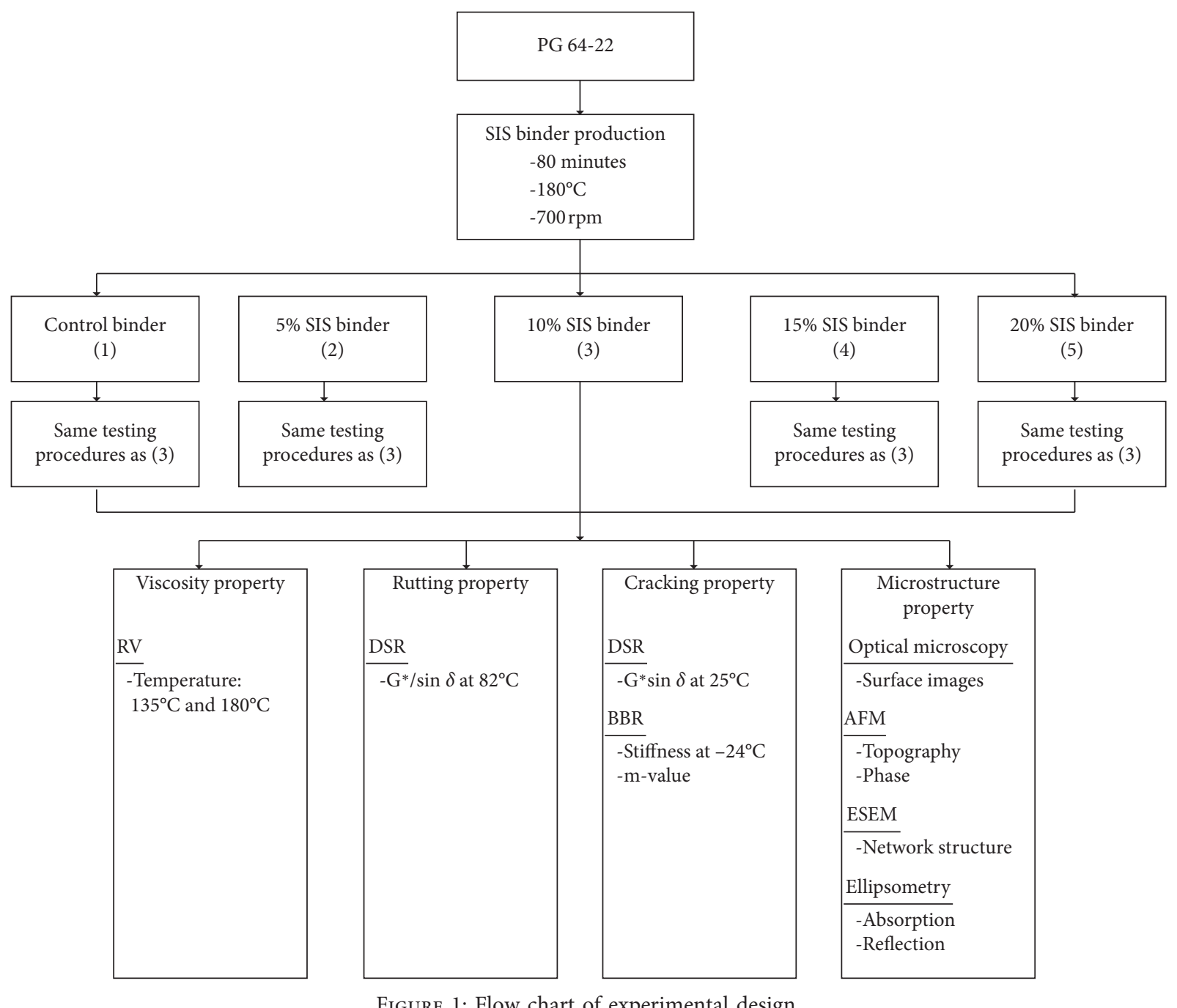

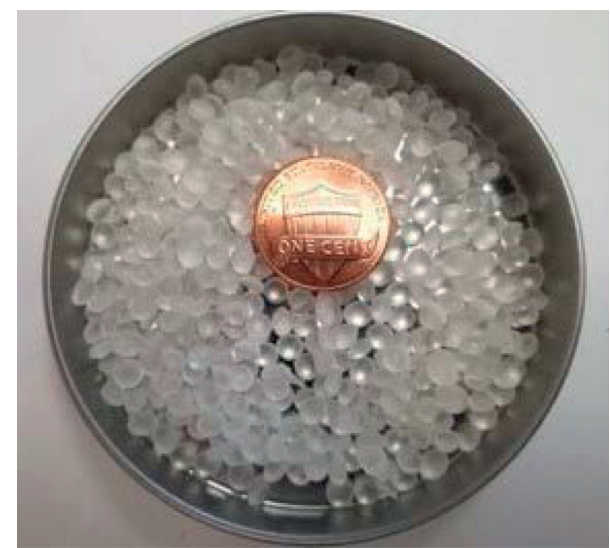

FIGURE 2: SIS (styrene-isoprene-styrene).

or ESEM was developed by G. Danilatos in the mid-eighties [15]. The term "environment" stems from the idea that this technique allows imaging of samples by varying the sample environment through a range of pressures, temperatures, and gas compositions. ESEM provides all of the performance advantages of a conventional SEM but removes the high vacuum constraint on the sample environment. In ESEM, wet, oily, dirty, non-conductive samples can be examined in their natural state without any damage to surface or surface preparation [16, 17]. ESEM provides high resolution scanning secondary electron imaging in almost any gaseous environment at pressure as high as 50 Torr and temperature as high as $1500^{\circ} \mathrm{C}$ [16]. Therefore, electron imaging of asphalt can only be performed in ESEM without any concerns of surface damage and conductive coating. In this study, JEOL (Model\#: JSM-6010PLUS/LA) ESEM is used to examine the surface microstructure of SIS binder. The degree of magnification is chosen to be $1000 x$. The scan sizes used are $10 \mu \mathrm{m}$. The equipment settings used for scanning are as follows: $5-10 \mathrm{kV}$; pressure, $40 \mathrm{~Pa}$. Figure 5 shows the JEOL ESEM.

2.6. Ellipsometry. Complex refractive index of material which comprises a refractive index and extinction or absorption coefficient is used to characterize the interaction of light with any material surface $[18,19]$. Spectroscopic ellipsometry is known as a powerful tool for determining 
TABle 1: Properties of SIS modifier.

\begin{tabular}{lccc}
\hline Properties & Test method & Units & Typical value \\
\hline Styrene & TSRC/DEXO method & wt $\%$ & 15 \\
Diblock content & TSRC/DEXO method & wt $\%$ & 18 \\
Melt flow rate $\left(200^{\circ} \mathrm{C} / 5 \mathrm{~kg}\right)$ & ASTM D1238 & $\mathrm{g} / 10 \mathrm{~min}$ & 11 \\
Solution viscosity & ASTM D2196 & $\mathrm{cps}$ & 1240 \\
Ash & ASTM D5630 & $\mathrm{wt} \%$ & $\mathrm{MPa}$ \\
Tensile strength & TSRC/DEXO method & $\mathrm{MPa}$ & 25 \\
$300 \%$ modulus & TSRC/DEXO method & $\%$ & 1.1 \\
Elongation & TSRC/DEXO method & Shore A & 1250 \\
Hardness & ASTM D2240 & $\mathrm{g} / \mathrm{cm}^{3}$ & 33 \\
Bulk density & ASTM D 1895 & $\mathrm{~kg} / \mathrm{m}^{3}$ & $0.55(4113 \mathrm{~A})$ \\
Specific gravity & ASTM D792 & 0.92 \\
\hline
\end{tabular}

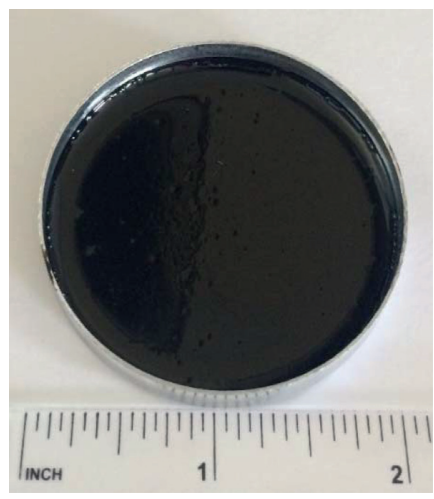

(a)

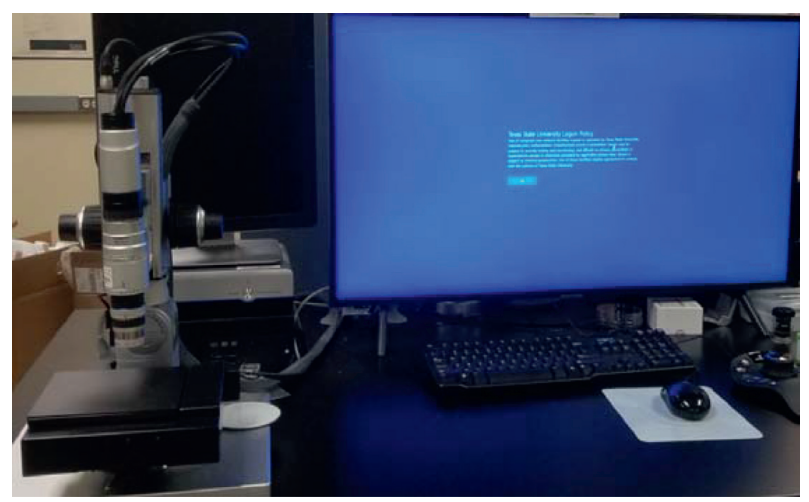

(b)

Figure 3: (a) Asphalt sample for morphology investigation and (b) Hirox digital microscope.

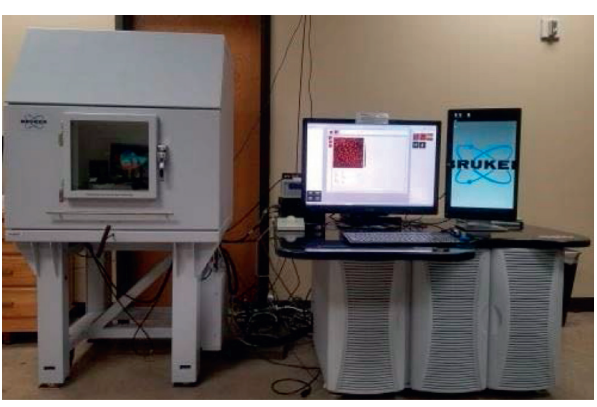

Figure 4: Atomic force microscopy (AFM).

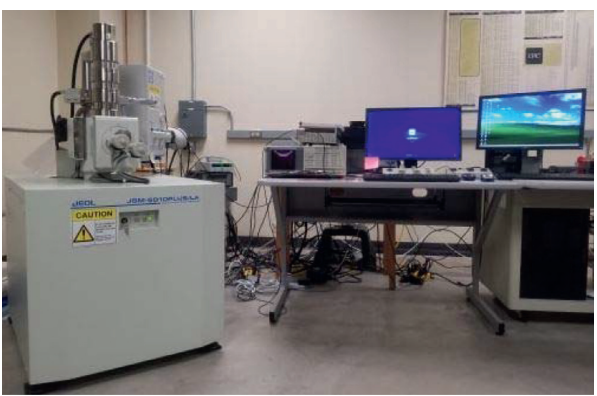

FIgURE 5: Environmental electron scanning microscopy (ESEM). both refractive index $(n)$ and extinction coefficient $(k)$ of any thin film $[20,21]$. It is specifically measuring the change of state of polarization for light reflected at an oblique angle from the surface of a sample [18]. The polarization change results in terms of phase and using appropriate algorithms changes are analyzed from the various optical parameters to obtain film thickness, refractive index $(n)$, and optical loss (k) [12]. The complex refractive index is given by [18]

$$
n(\lambda)=n-i k .
$$

The real part of the refractive index $(n)$ describes how the speed of light changes as it enters the material, and the extinction coefficient $(k)$ describes how light is absorbed or scattered (Elton 2007).

Thin films of asphalt binders are made on glass substrate $(20 \mathrm{~mm} \times 20 \mathrm{~mm})$ to analyze asphalt thin films using spectroscopic ellipsometry, as shown in Figure 6. A sample is prepared by pouring melted binder on the surface of a glass substrate. All binders are preconditioned by controlled heating at $170^{\circ} \mathrm{C}$ in an oven for 10 minutes and then a drop $(\sim 10 \mathrm{~mL})$ of liquid asphalt is poured on the glass substrate. J. A Woollam (model M 2000 UI) Ellipsometer is used to collect the variable angle spectroscopic ellipsometry (VASE) data in reflectivity mode. Data are collected in the wavelength range of $290 \mathrm{~nm}-1690 \mathrm{~nm}$ in three different angles $\left(55^{\circ}, 60^{\circ}\right.$, and $\left.65^{\circ}\right)$. A model is created, and measured data are fitted with the model 


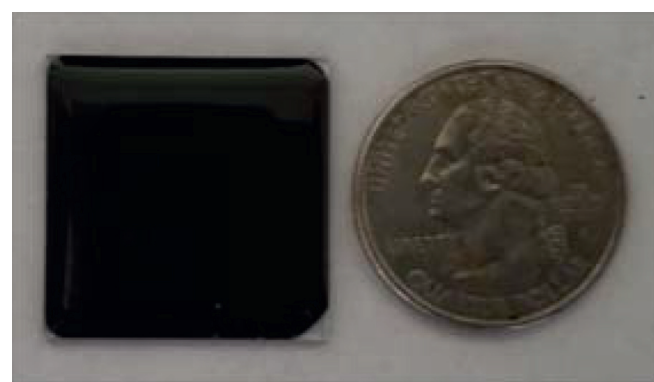

(a)

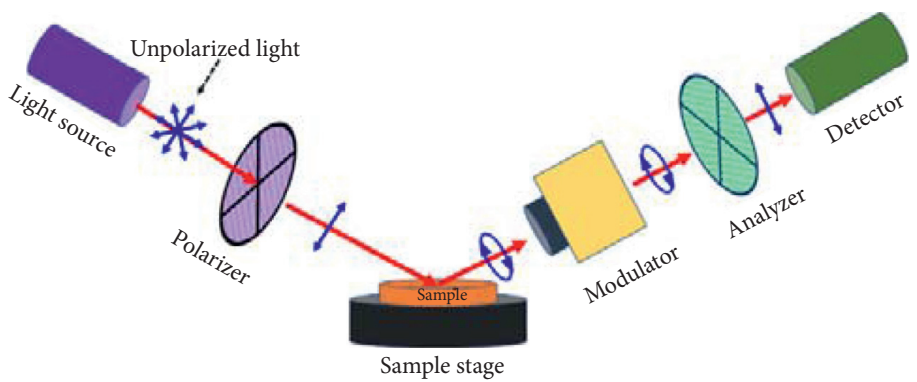

(b)

FIGURE 6: Ellipsometry: (a) prepared sample and (b) schematic diagram of spectroscopic ellipsometry system [20].

generated spectra to obtain optical constants, $n$ and $k$. The goal of this step is to obtain least mean square error (MSE) between the model generated spectra and the actual spectra which would help to achieve the true optical constant for layer material. Due to the unknown optical properties of the asphalt binder, a simple model of glass with absorbing film is used at first. Later, the model is chosen as a Cauchy model for glass and B-spline model for the asphalt and a global fit is performed [23]. For each of the films, the mean square error is less than 1. Optical constants for the entire measurement wavelength range are then plotted for SIS binders.

\section{Results and Discussions}

\subsection{Rheological Properties}

3.1.1. Viscosity Property. The viscosity of asphalt binder at high temperature is considered to be an important property to decide working temperature because it reflects the binder's ability to be pumped through an asphalt plant, thoroughly coat aggregate in a HMA mixture, and be placed and compacted to form a new pavement surface (Asphalt Institute 2003). Figure 7 illustrates the standard RV test results for SIS binders at $135^{\circ} \mathrm{C}$ and $180^{\circ} \mathrm{C}$. It is evident that the addition of SIS to the asphalt binder increases the binder viscosity for both testing temperatures. The viscosity values of PG $64-22$, SIS $5 \%$, and SIS $10 \%$ at $135^{\circ} \mathrm{C}$ are found to be 635,2028 , and $7008 \mathrm{cP}$, respectively. The addition of $5 \%$ and $10 \%$ content of SIS increased the viscosity of the binder by $219 \%$ and $1003 \%$, respectively. The viscosity of $15 \%$ and $20 \%$ SIS binder could not be measured at $135^{\circ} \mathrm{C}$. However, the viscosity results at $180^{\circ} \mathrm{C}$ showed that there is insignificant difference after adding more than $15 \%$ of SIS content.

The statistical significance of the change in the viscosity as a function of SIS content is examined and the results are shown in Table 2 . At $135^{\circ} \mathrm{C}$, the difference among all the SIS binders is found to have statistically significant. The difference between 15\% SIS and 20\% SIS binder is observed to be statistically insignificant at $180^{\circ} \mathrm{C}$.

3.1.2. Rutting Property. The higher $\mathrm{G} * / \sin \delta$ values from the DSR test indicate that the binders are less susceptible to rutting or permanent deformation at high pavement temperature (Asphalt Institute 2003). The $\mathrm{G} * / \sin \delta$ values of unaged SIS binders were measured at $82^{\circ} \mathrm{C}$. Figure 8 shows

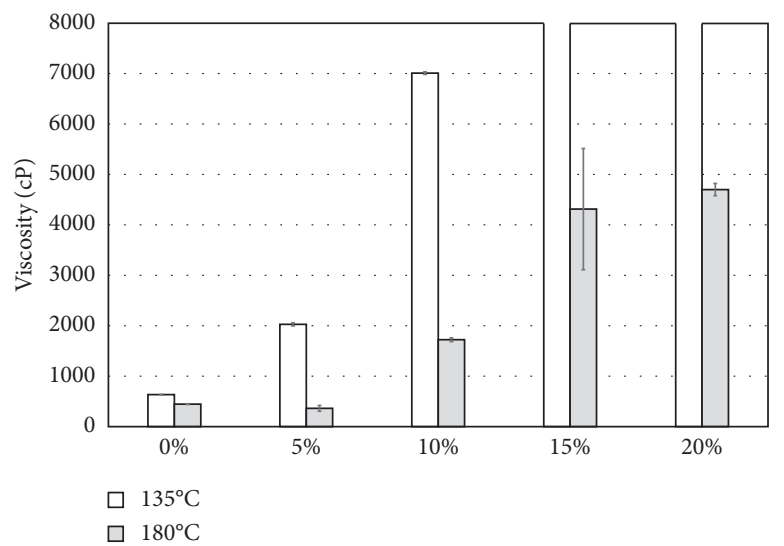

Figure 7: Viscosity of SIS binders at $135^{\circ} \mathrm{C}$ and $180^{\circ} \mathrm{C}$.

TABLE 2: Statistical analysis results of the viscosity value as a function of SIS content: (a) $135^{\circ} \mathrm{C}$ and (b) $180^{\circ} \mathrm{C}$.

\begin{tabular}{cccccc}
\hline Viscosity & SIS 0\% & SIS 5\% & SIS 10\% & SIS 15\% & SIS 20\% \\
\hline SIS 0\% & - & S & S & S & S \\
SIS 5\% & & - & S & S & S \\
(a) SIS 10\% & & & - & S & S \\
SIS 15\% & & & & - & S \\
SIS 20\% & & & & & - \\
\hline SIS 0\% & - & N & S & S & S \\
SIS 5\% & & - & S & S & S \\
(b) SIS 10\% & & & - & S & S \\
SIS 15\% & & & & - & N \\
SIS 20\% & & & & & - \\
\hline
\end{tabular}

$\mathrm{N}$ : nonsignificant; S: significant.

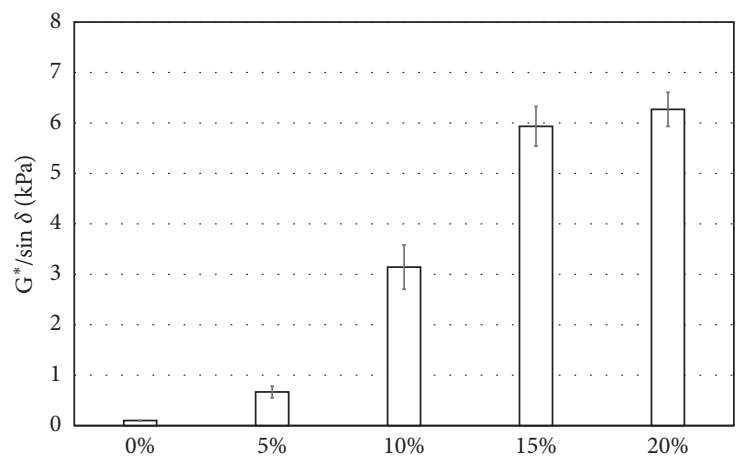

Figure $8: \mathrm{G} * / \sin \delta$ of SIS binders at $82^{\circ} \mathrm{C}$. 
the $\mathrm{G} * / \sin \delta$ values of SIS binders. It is evident from the figure that the addition of SIS modifier significantly increases the rutting resistance of the binder. The $\mathrm{G} * / \sin \delta$ values of PG $64-22$, SIS $5 \%$, SIS $10 \%$, SIS $15 \%$, and SIS $20 \%$ at $82^{\circ} \mathrm{C}$ are found to be $0.1,0.7,3.1,5.7$, and $6.5 \mathrm{kPa}$, respectively. The addition of $5 \%, 10 \%, 15 \%$, and $20 \%$ SIS content increased the rutting resistance by $600 \%, 3000 \%, 5600 \%$, and $6400 \%$, respectively. It means that the SIS has a positive effect on the rutting resistance at high temperature which causes an increase in the complex modulus of the binders. However, the percentage improvement of rutting resistance after 15\% addition of SIS modifier is found to be less significant. Table 3 presents the statistical significance of the change in the $\mathrm{G} * / \sin \delta$ as a function of SIS content. In general, the data indicate that SIS content has a significant effect on $G *$ / $\sin \delta$.

\subsubsection{Cracking Property}

(1) Fatigue Cracking Property. In general, the lower G*sin $\delta$ values are considered to be desirable attributes from the standpoint of fatigue cracking resistance (The Asphalt Institute 2003). The $\mathrm{G} * \sin \delta$ values of the SIS binders are determined using the DSR at $25^{\circ} \mathrm{C}$ and the results are illustrated in Figure 9. The $\mathrm{G} * \sin \delta$ values are found to be $1210,1101,146,140$, and $97 \mathrm{kPa}$ for the binders of control (PG 64-22), SIS 5\% (PG 64$22+5 \%$ SIS), SIS 10\% (PG 64-22 + 10\% SIS), SIS 15\% (PG 64$22+15 \%$ SIS), and SIS 20\% (PG 64-22+20\% SIS), respectively. With the increase of SIS percentage, the binder is found to have more cracking resistance.

Using one-way ANOVA, the statistical significance of the change in the $\mathrm{G} * \sin \delta$ values is examined and shown in Table 4. The data indicate that the SIS content has a significant effect on the $\mathrm{G} * \sin \delta$ values. Meanwhile, the difference among the binders of SIS 10\%, SIS 15\%, and SIS $20 \%$ is found to be statistically insignificant.

(2) Stiffness. From the BBR tests at $-24^{\circ} \mathrm{C}$, the stiffness and $m$-value of SIS binders at original state are calculated and results are illustrated in Figures 10 and 11, respectively. It is found that the addition of SIS into the asphalt binder significantly decreases the low temperature stiffness. The addition of $5 \%$ SIS and $10 \%$ SIS resulted in decreasing the stiffness of control PG $64-22$ binder by $26 \%$ and $51 \%$, respectively. Also, with the percentage of SIS modifier increased, the low temperature stiffness of the binder is observed to be decreased.

The one-way ANOVA is conducted to investigate the statistical change in the stiffness as a function of SIS content and the results are summarized in Table 5. The binder with 10\% SIS is statistically significant compared to the binders with SIS $15 \%$ and SIS $20 \%$. On the other hand, the difference between SIS $15 \%$ and SIS $20 \%$ is statistically insignificant at the $5 \%$ level.

\subsection{Microscopy Properties}

3.2.1. Optical Microscopy Analysis. Figures 12(a)-12(e) illustrate the surface images of the prepared SIS binder sample
TABLE 3: Statistical analysis results of the $G * / \sin \delta$ value as a function of SIS content.

\begin{tabular}{lccccc}
\hline $\mathrm{G} * / \sin \delta$ & SIS 0\% & SIS 5\% & SIS 10\% & SIS 15\% & SIS 20\% \\
\hline SIS 0\% & - & S & S & S & S \\
SIS $5 \%$ & & - & S & S & S \\
SIS $10 \%$ & & & - & S & S \\
SIS 15\% & & & & - & $\mathrm{N}$ \\
SIS 20\% & & & & & - \\
\hline
\end{tabular}

$\mathrm{N}$ : nonsignificant; S: significant.

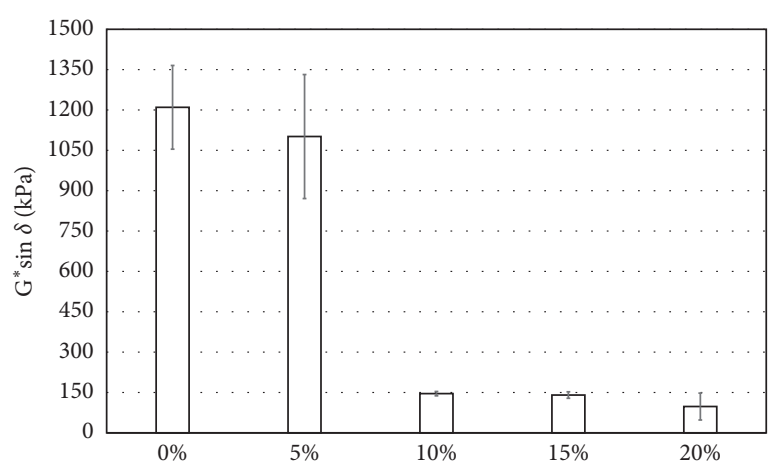

Figure 9: $\mathrm{G} * \sin \delta$ of SIS binders at $25^{\circ} \mathrm{C}$.

TABLE 4: Statistical analysis results of the $\mathrm{G} * \sin \delta$ value as a function of SIS content.

\begin{tabular}{lccccc}
\hline $\mathrm{G} * \sin \delta$ & SIS $0 \%$ & SIS $5 \%$ & SIS $10 \%$ & SIS $15 \%$ & SIS $20 \%$ \\
\hline SIS $0 \%$ & - & $\mathrm{N}$ & $\mathrm{S}$ & $\mathrm{S}$ & $\mathrm{S}$ \\
SIS $5 \%$ & & - & $\mathrm{S}$ & $\mathrm{S}$ & $\mathrm{S}$ \\
SIS $10 \%$ & & & - & $\mathrm{N}$ & $\mathrm{N}$ \\
SIS $15 \%$ & & & & - & $\mathrm{N}$ \\
SIS 20\% & & & & & - \\
\hline
\end{tabular}

N: nonsignificant; S: significant.

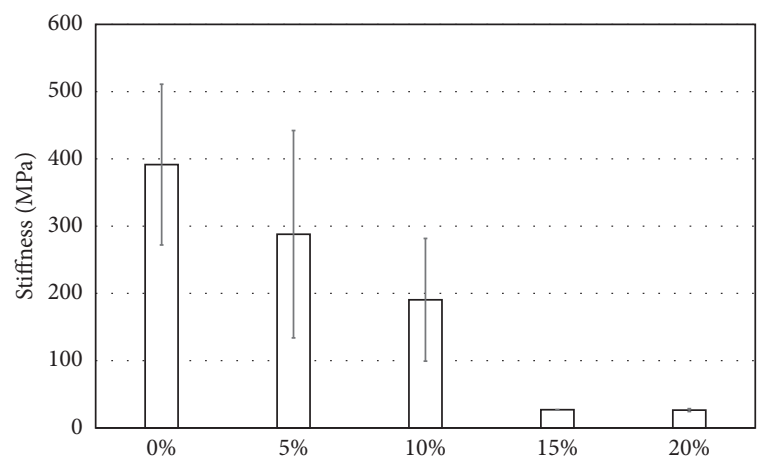

Figure 10: Stiffness of SIS binders at $-24^{\circ} \mathrm{C}$.

at its original state. The surface image of control binder PG 64-22 or SIS $0 \%$ shows blue spots homogeneously spread all over the surface which are actually the bee structure and evident in AFM images. The addition of SIS modifier exhibited a new elongated phase along with bee structure. 


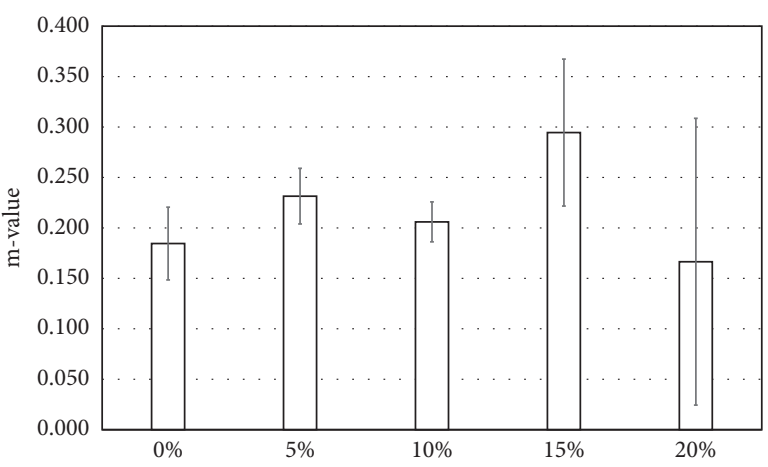

Figure 11: m-value of SIS binders at $-24^{\circ} \mathrm{C}$.

TABLE 5: Statistical analysis results of the stiffness value as a function of SIS content.

\begin{tabular}{lccccc}
\hline Stiffness & SIS 0\% & SIS 5\% & SIS 10\% & SIS 15\% & SIS 20\% \\
\hline SIS 0\% & - & $\mathrm{N}$ & $\mathrm{S}$ & $\mathrm{S}$ & $\mathrm{S}$ \\
SIS 5\% & & - & $\mathrm{N}$ & $\mathrm{S}$ & $\mathrm{S}$ \\
SIS 10\% & & & - & $\mathrm{S}$ & $\mathrm{S}$ \\
SIS 15\% & & & & - & $\mathrm{N}$ \\
SIS 20\% & & & & & - \\
\hline
\end{tabular}

$\mathrm{N}$ : nonsignificant; S: significant.

With further addition of SIS content of $10 \%$, the density of new phase increased and at $15 \%$ content the new oval phase is evident in Figure 12(d). The addition of $20 \%$ content of SIS shows the homogeneous spread of oval phase throughout the sample surface.

3.2.2. AFM Analysis. Figures 13(a)-13(j) show the topographic and phase images of SIS binders at a scan size of $20 \mu \mathrm{m}$ after $24 \mathrm{~h}$. Figure 13(a) presents the topographic image of PG 64-22 which consists of a microstructure which looks like a sequence of hills and valleys. This distinct feature is known as bee-like structure and it is more evident in the phase image [24]. As shown in Figure 13(b), the phase image consists of three different features which are the catana phase (bee-like structure), the peri phase (the area surrounding the bee structure), and the para phase (the red solvent region).

The catana and peri phase constitutes the dispersed domains which is responsible for the stiffness of the binder [25]. It has more stiffness compared to the para phase or matrix. It can be observed from the topography image that the control binder has increased size of bee structure which are embedded on the surface in an organized way. The phase image gives more insight of the dispersion of dispersed domains and the matrix of the binder. It is clearly evident that the control binder consists of large area of dispersed domains compared to the matrix.

Figures 13(c) and 13(d) present the topographic and phase image of the binder with $5 \%$ SIS modifier. In the topographic image, the number of bee structures is reduced and it is more evident in phase image. From the previous studies [26], it is found that microcrystalline waxes and waxy molecules are responsible for the bee structures. The addition of SIS modifier might dissolve the waxy molecules which contributes to the disappearance of the bee-like structures and make it less stiff compared to the control binder.

Figures 13(e) and 13(f) illustrate the topographic and phase image of the binder containing 10\% SIS modifier. The addition of further amount of SIS modifier decreased the size and width of the bee structure (Figure 13(e)). However, a new phase which is an oval shape is observed to evolve in topography image. On the other hand, in the phase image the area of matrix phase significantly increases and the peri phase surrounding bee structure also gets reduced.

Figures $13(\mathrm{~g})$ and 13(h) show the further addition of SIS modifier (15\% of the binder weight) reduced the size and number of bee structures. The new phase is identified in Figure 13(e); the oval shape appears to be brighter for this binder type. The area of dispersed domain is reduced significantly and the para phase or the solvent region covers most of the area of the phase image. It indicates that the addition of SIS modifier has a significant effect on the micromorphology of PG 64-22.

Figures 13(i) and 13(j) present the topographic and phase image of binder with $20 \%$ of SIS modifier. The trend is consistent with the earlier findings as the number of bee structures appears to be less in the topographic image. However, there is no significant distinction between the binders with $15 \%$ and $20 \%$. Also, the difference between the rheological data of these two binders is observed to be nonsignificant. The new oval phase is observed to have increased in size. Although the peri phase is found to be expanded compared to Figure 13(h), the number of bee structures appeared to be consistent.

The aforementioned discussions of microstructural properties of the binder modified with SIS modifier are found to be consistent with the stiffness properties of the binder. Among all the binder types, the control binder has the highest stiffness and as the amount of SIS modifier increases, the binder becomes less stiff based on the difference of contrast between dispersed domains and matrix.

3.2.3. ESEM Analysis. ESEM images are captured for the SIS binder at original state. Figure 14 shows ESEM image of the binder modified with SIS modifier. Figure 14(a) shows the ESEM image of control PG 64-22. The formation of threedimensional entangled network structure has been observed after several minutes of beam exposure in ESEM. The fibrils of the network structure consist of high molecular weight asphaltene/resin micelles and contribute significantly to the fracture behavior of asphalt binder [27]. It can be observed that the fibril structures are relatively denser and thicker for the control binder.

Figure 14(b) shows the image of binder containing $5 \%$ of SIS modifier. A careful observation shows that, with the addition of SIS modifier to the binder, the fibrils of the network structure appear to become loose and an evolution of new phase is identified. Although the phase does not appear to be dense at this stage, a distinction can be observed through the images of with and without SIS modifier. 


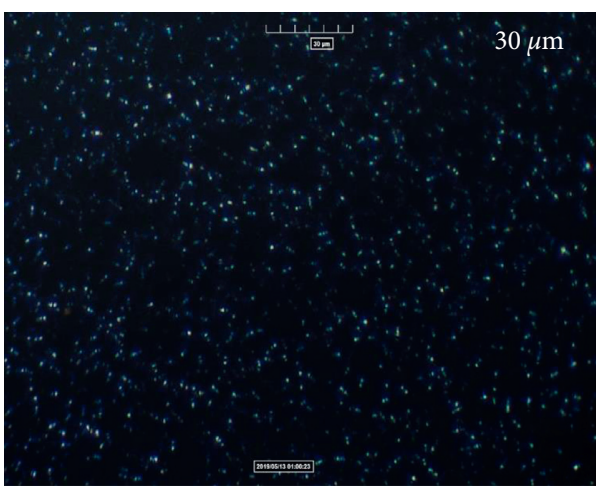

(a)

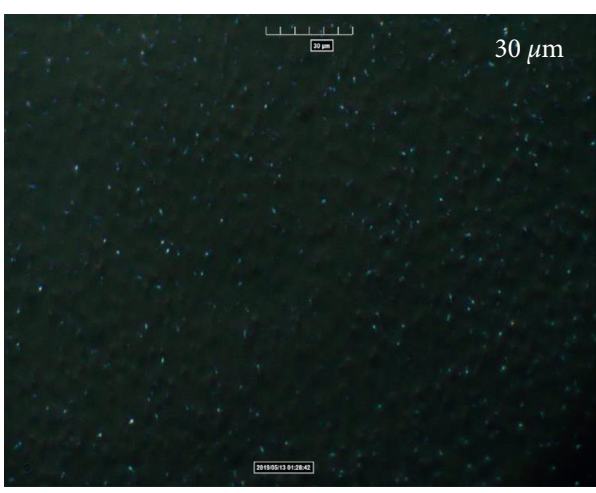

(c)

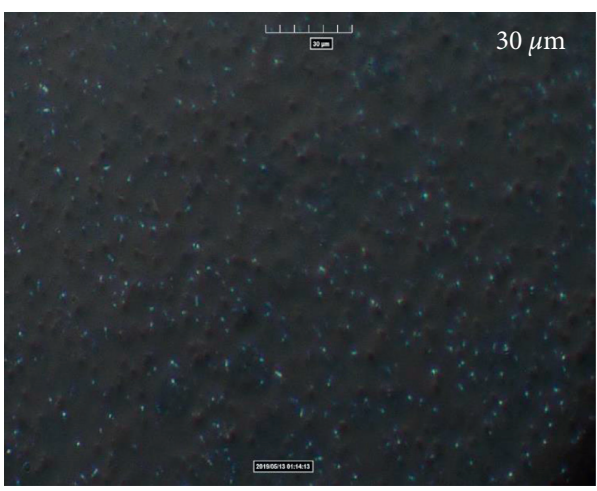

(b)

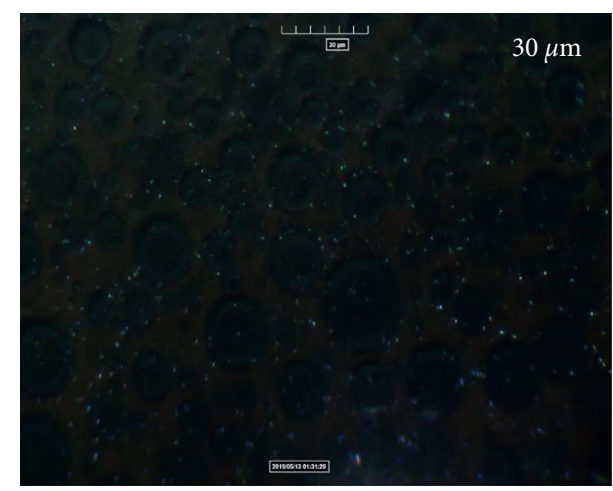

(d)

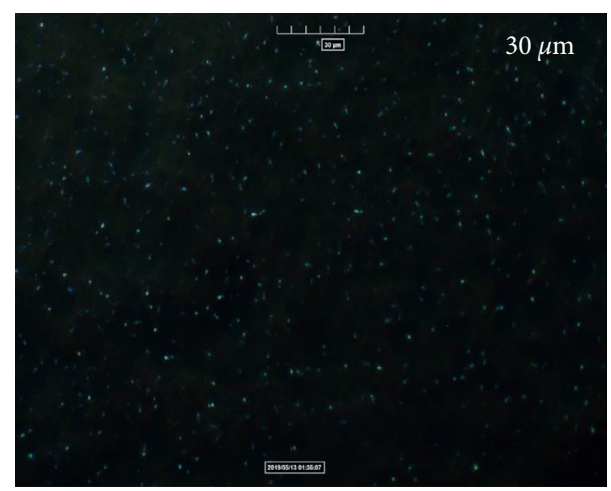

(e)

FIGURE 12: Optical microscopy images at original state: (a) SIS 0\%, (b) SIS 5\%, (c) SIS 10\%, (d) SIS $15 \%$, and (e) SIS $20 \%$.

Figure 14(c) presents image of binder containing 10\% of SIS modifier. The distinct round oval phase is evident from the image. The diameter of fibrils is observed to be decreased and shows an evolution of the oval phase with the percentage increase of SIS modifier. The network structure appears to be a spider net where the fibrils are the net and the oval phase is evolving from the empty space of the net.

Figure 14(d) illustrates the image captured on the binder with $15 \%$ of SIS modifier. The oval phase is observed to have an increased diameter and bulging out from the network structure. As a result, the organized fibril of the network structure becomes disoriented in size and shape.

Figure 14(e) presents the ESEM image of the binder containing $20 \%$ of SIS polymer. As discussed earlier about the bulging out of the oval phase of the binder, it is clearly more evident from this image. The oval phase becomes denser and the number appears to be increased significantly. The fibril structure is almost replaced by the oval phase.

In summary, SIS modifier has a significant effect on the microstructure of the control binder. The evolution of oval phase is certainly believed to have a contribution towards the stiffness of the binder. The low temperature properties obtained from BBR show that the binder becomes more cracking resistant with the percentage increase of SIS modifier which also resembles the increase of oval phase in the binder microstructure due to the amount of SIS modifier.

3.2.4. Ellipsometry Analysis. Figure 15 illustrates the refractive index and extinction coefficient of the binders. The 


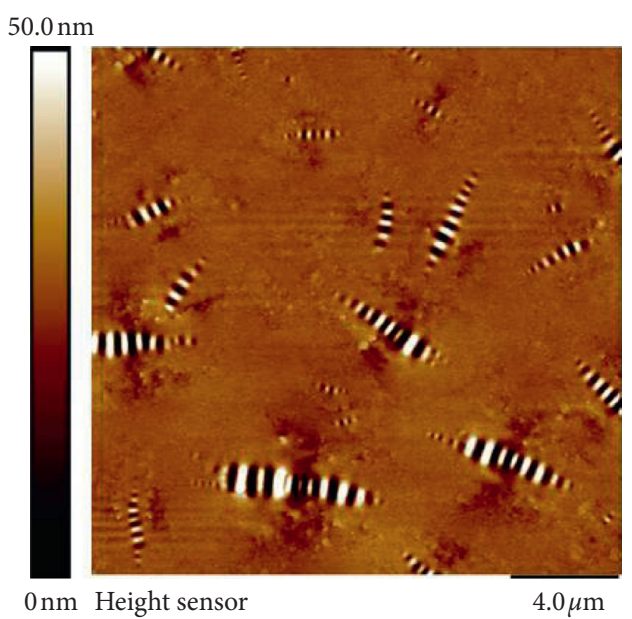

(a)

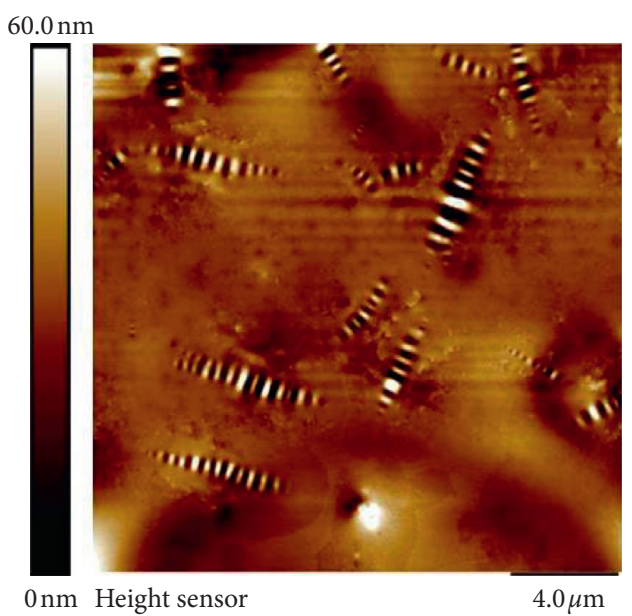

(c)

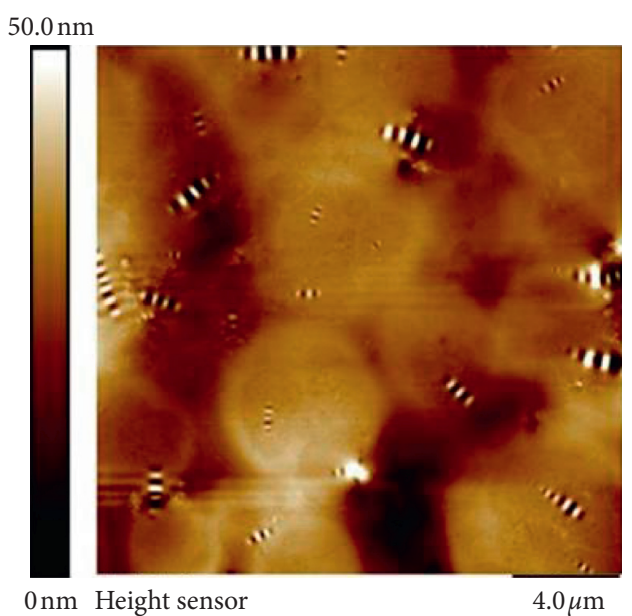

(e)

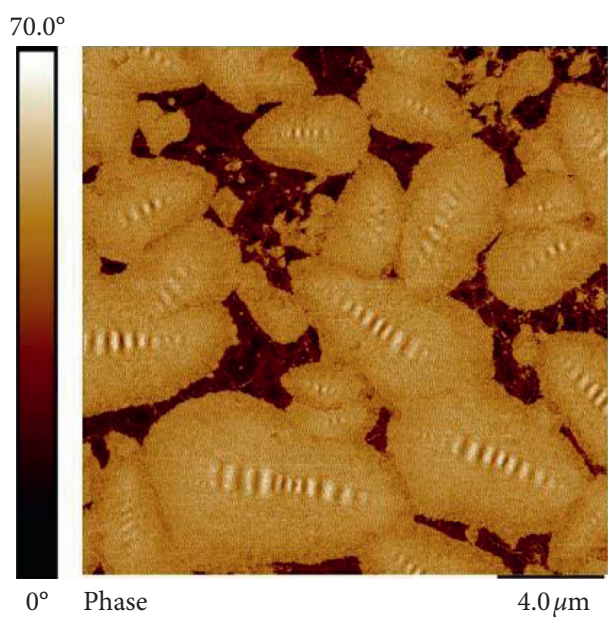

(b)

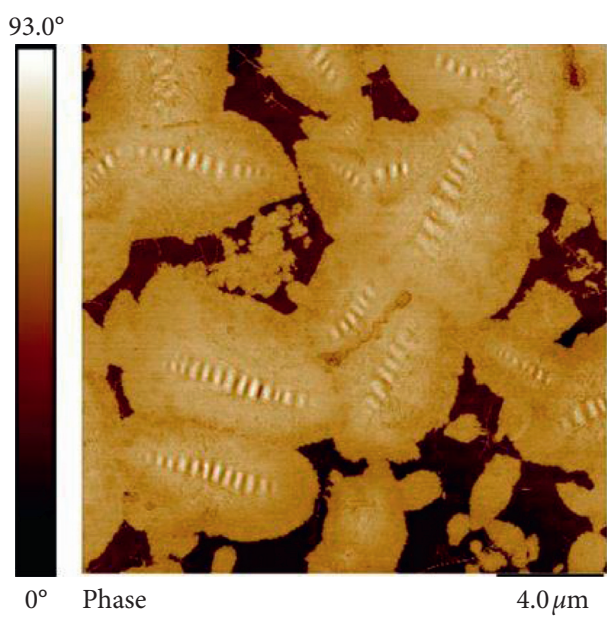

(d)

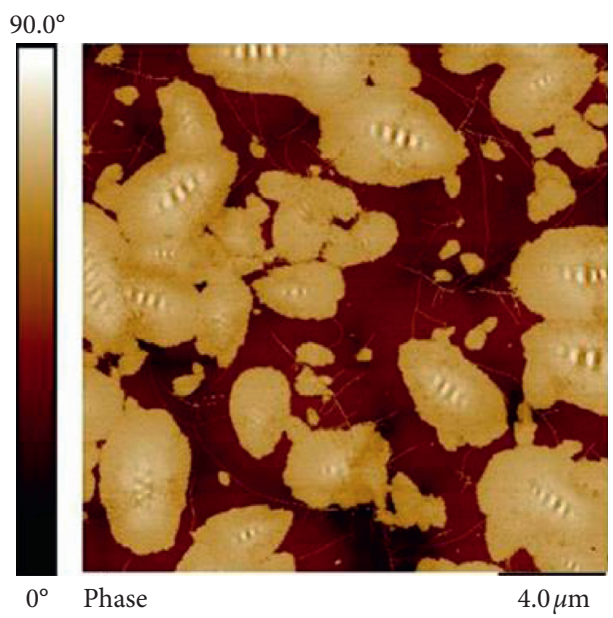

(f)

Figure 13: Continued. 


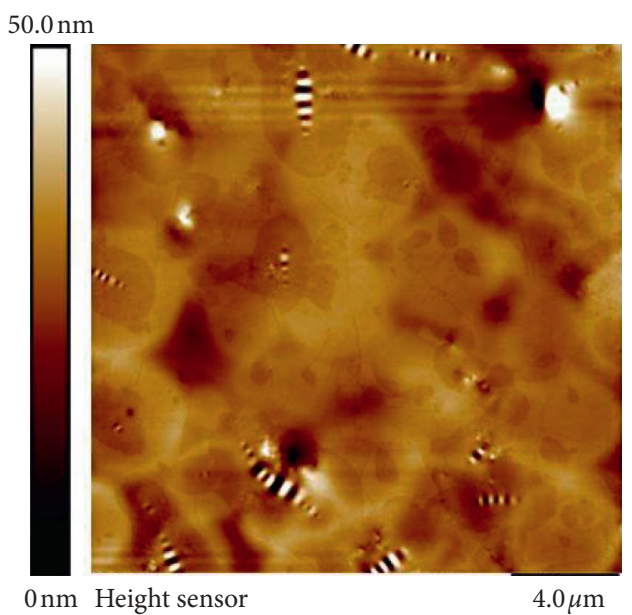

(g)

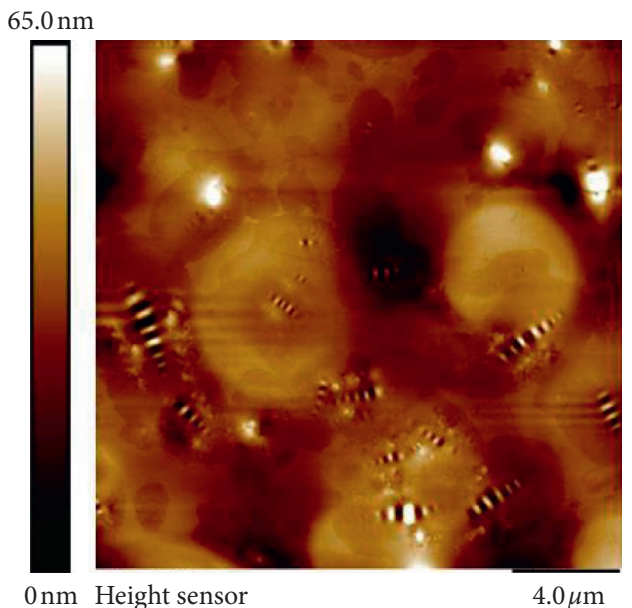

(i)

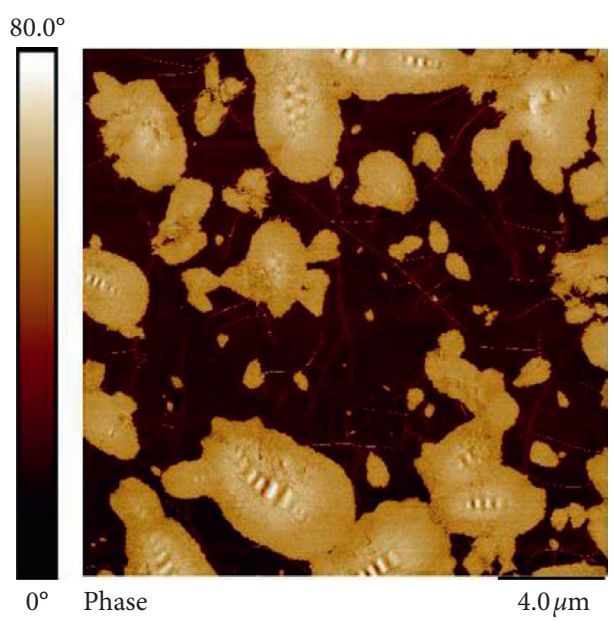

(h)

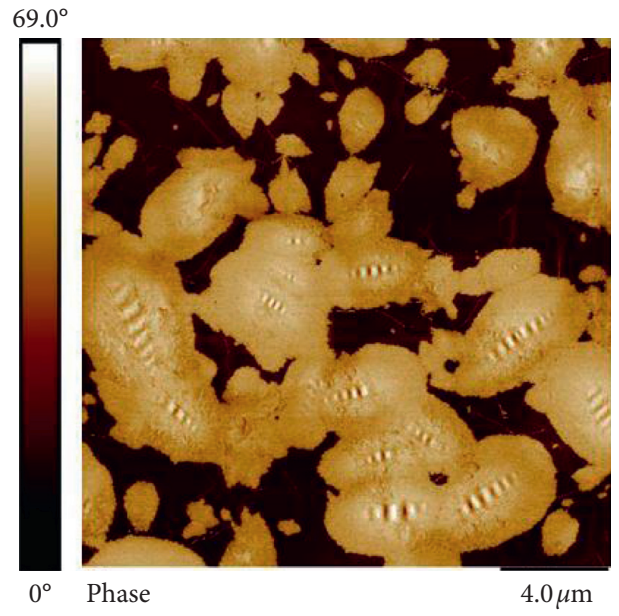

(j)

FIGURE 13: SIS 0\% at original state: (a) topographical image; (b) phase image. SIS 5\% at original state: (c) topographical image; (d) phase image. SIS 10\% at original state: (e) topographical image; (f) phase image. SIS 15\% at original state: (g) topographical image; (h) phase image. SIS $20 \%$ at original state: (i) topographical image; (j) phase image.

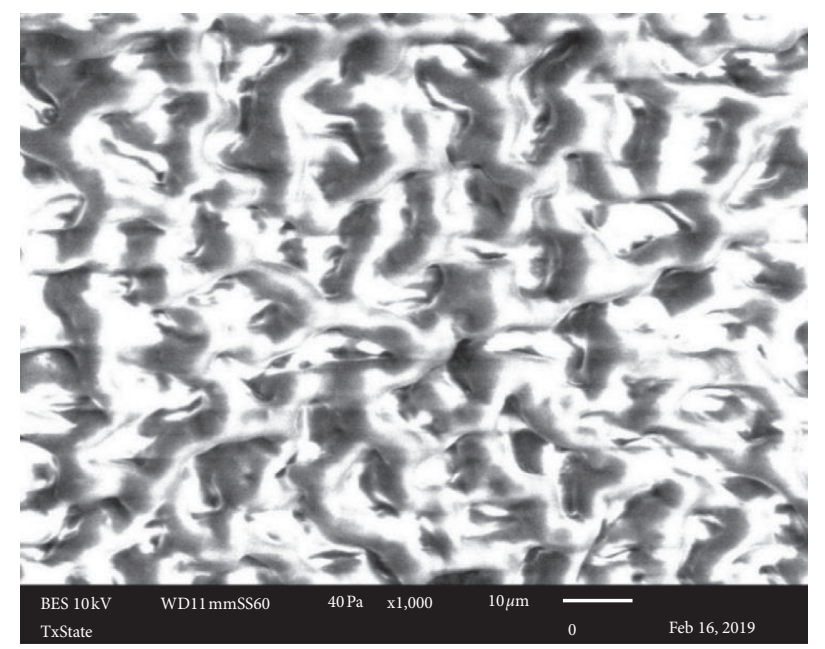

(a)

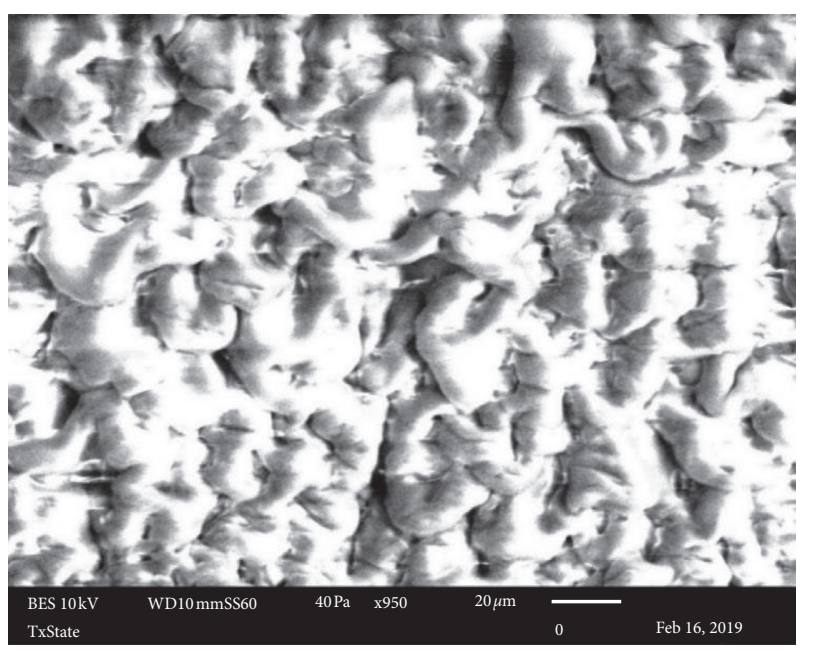

(b)

FIgURE 14: Continued. 


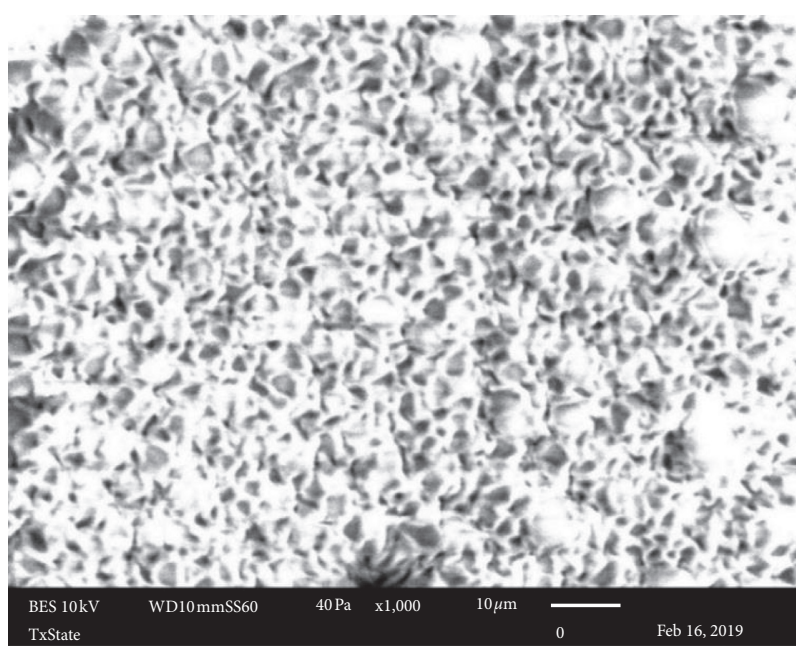

(c)

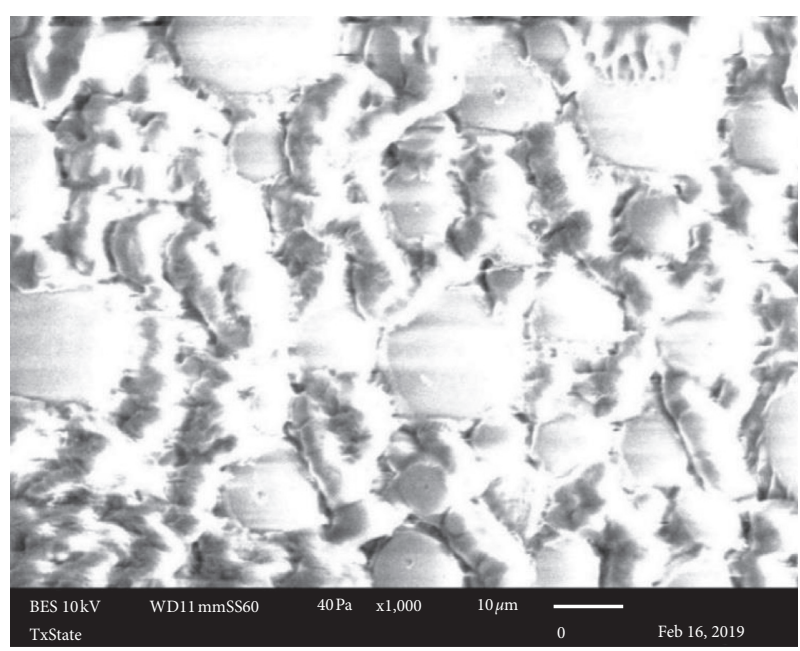

(d)

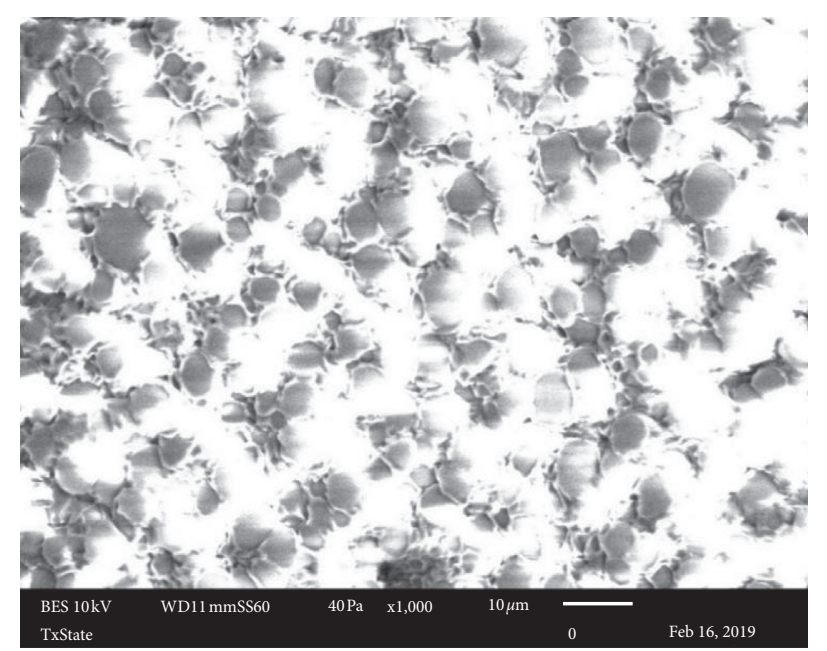

(e)

FIGURE 14: ESEM images at original state: (a) SIS 0\%, (b) SIS 5\%, (c) SIS 10\%, (d) SIS 15\%, and (e) SIS $20 \%$.

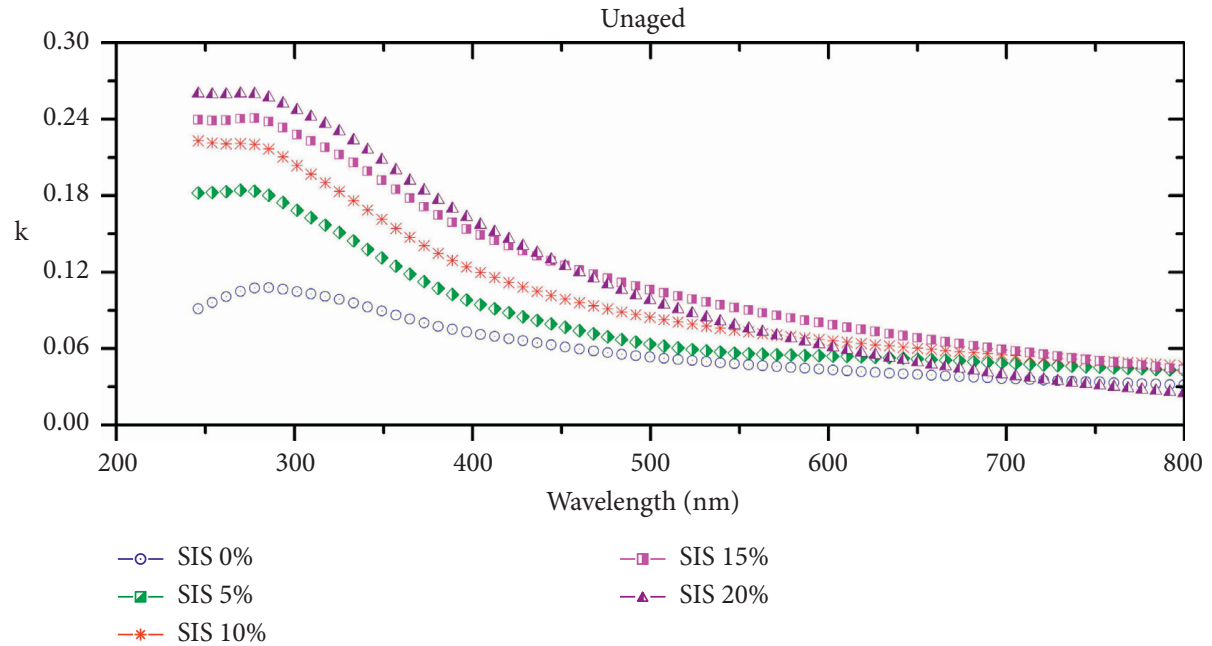

(a)

FIGURE 15: Continued. 


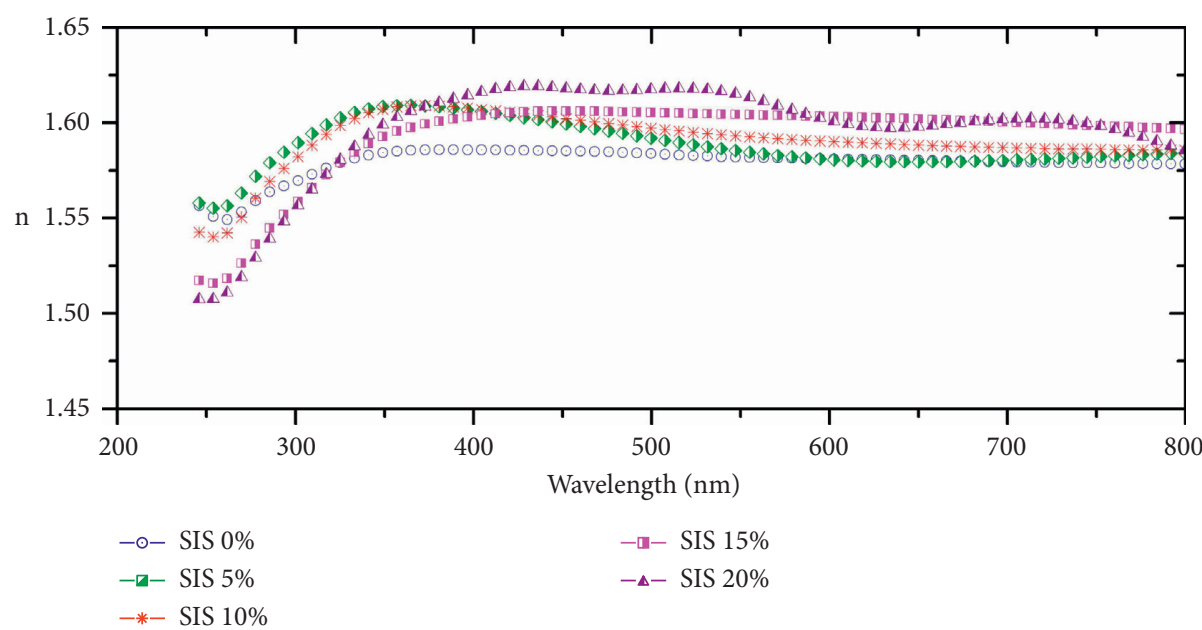

(b)

FIGURE 15: Variation in optical constants $(n, k)$ of SIS binders.

extinction coefficient of all the binders is observed to have a decreasing function of wavelength. The binder with $20 \%$ of SIS modifier exhibited the highest absorption whereas the value is the lowest for the control binder at UV wavelength. In general, the same trend is observed at visible wavelength $(400-700 \mathrm{~nm})$ as well. The opposite trend is found with all the binders in terms of their refractive index.

\section{Conclusions}

This study is to investigate the physical, rheological, and microstructural properties of SIS binder. The binders are produced using $0 \%, 5 \%, 10 \%, 15 \%$, and $20 \%$ of SIS by the weight of the control PG 64-22 binder. The viscosity property is determined by RV, rheology and stiffness properties are measured by DSR and BBR, respectively, and micromorphology is investigated using optical microscopy, AFM, and ESEM. Ellipsometry is used to measure the reflection and absorption properties of the SIS binder. Based on the result of these tests, the conclusions are drawn for the materials used in this study as follows:

(1) The addition of SIS into asphalt binder can significantly increase the viscosity of binders. With the SIS percentage increased, the binder viscosity increases at both testing temperatures. However, the viscosity of SIS binder seems to have insignificant change after adding more than $15 \%$ of SIS content.

(2) The amount of SIS modifier has a positive effect on the rutting resistance at high temperature. The addition of 5\% SIS improved the rutting performance of the original PG 64-22 binder by $600 \%$ and further addition of SIS content increased the percentage improvement significantly.

(3) The addition of SIS into asphalt binder can significantly decrease the $\mathrm{G} * \sin \delta$ and creep stiffness of SIS binder at low temperature which can ensure better cracking resistance of asphalt binder. The $\mathrm{G} * \sin \delta$ values are found to be decreased by $9 \%, 87 \%, 88 \%$, and $91 \%$ with the addition of $5 \%, 10 \%, 15 \%$, and $20 \%$, respectively.

(4) In general, the results indicated that the SIS content of $15 \%$ might be considered as an optimum content for future studies.

(5) AFM images show the micromorphology of the binder modified with SIS based on the difference of contrast between dispersed domains and matrix. The stiffness and microstructure properties are observed to have a correlation.

(6) ESEM images show the network structure and evolution of a new oval phase which has a significant effect on the binder stiffness properties. With the percentage increase of SIS modifier, the oval phase becomes more dominant in the network structure and is observed to play a vital role in the cracking resistance of the SIS binder.

(7) In general, ellipsometry results show that, with the higher SIS content, the binder exhibited higher absorption at UV wavelength.

\section{Data Availability}

The data used to support the findings of this study are included within the article.

\section{Conflicts of Interest}

There are no conflicts of interest regarding the publication of this paper.

\section{Acknowledgments}

This research was supported by a grant from a government funding project (2020 National Highway Pavement Management System). 


\section{References}

[1] G. Polacco, S. Filippi, F. Merusi, and G. Stastna, "A review of the fundamentals of polymer-modified asphalts: asphalt/ polymer interactions and principles of compatibility," Advances in Colloid and Interface Science, vol. 224, pp. 72-112, 2015.

[2] J. Zhu, B. Birgisson, and N. Kringos, "Polymer modification of bitumen: advances and challenges," European Polymer Journal, vol. 54, pp. 18-38, 2014.

[3] H. H. Kim, M. Mazumder, and S.-J. Lee, "Recycling of aged asphalt binders with wax warm additives," Road Materials and Pavement Design, vol. 19, no. 5, pp. 1203-1215, 2018.

[4] H. H. Kim, M. Mazumder, M.-S. Lee, and S.-J. Lee, "Effect of blending time on viscosity of rubberized binders with wax additives," International Journal of Pavement Research and Technology, vol. 11, no. 6, pp. 655-665, 2018.

[5] F. Zhang, C. Hu, and Y. Zhang, "The research for SIS compound modified asphalt," Materials Chemistry and Physics, vol. 205, pp. 44-54, 2018.

[6] A. W. Ali, H. H. Kim, M. Mazumder, M. S. Lee, and S. J. Lee, "Multiple Stress Creep Recovery (MSCR) characterization of polymer modified asphalt binder containing wax additives," International Journal of Pavement Research and Technology, vol. 11, 2018.

[7] Y. Becker, M. P. Mendez, and Y. Rodriguez, "Polymer modified asphalt," Vision Technologica, vol. 9, no. 1, pp. 3950, 2001.

[8] M. Mazumder, H. Kim, and S.-J. Lee, "Performance properties of polymer modified asphalt binders containing wax additives," International Journal of Pavement Research and Technology, vol. 9, no. 2, pp. 128-139, 2016.

[9] R. Roque, B. Birgisson, C. Drakos, and G. Sholar, "Guidelines for use of modified binders," Report No. 4910-45054-964-12, pp. 7-13, University of Florida, Gainesville, Fl, USA, 2005.

[10] Y. Yildirim, "Polymer modified asphalt binders," Construction and Building Materials, vol. 21, no. 1, pp. 66-72, 2007.

[11] H. H. Kim, M. Mazumder, M. S. Lee, and S. J. Lee, "Evaluation of high-performance asphalt binders modified with SBS, SIS, and GTR," Advances in Civil Engineering, vol. 2019, Article ID 2035954, 11 pages, 2019.

[12] M. Mazumder, Characterization of crack sealant materials and implementation techniques, Ph.D. thesis, Texas State University, San Marcos, TX, USA, 2019.

[13] M. Mazumder, S. J. Lee, and M. S. Lee, "Properties of styreneisoprene-styrene (SIS) modified asphalt binder," in Proceedings of the 9th International Conference on Maintenance and Rehabilitation of Pavements-Mairepav9, pp. 597-605, Springer, Cham, Switzerland, June 2020.

[14] B. Bhushan and J. Qi, "Phase contrast imaging of nanocomposites and molecularly thick lubricant films in magnetic media," Nanotechnology, vol. 14, no. 8, p. 886, 2003.

[15] G. D. Danilatos, "Introduction to the ESEM instrument," Microscopy Research and Technique, vol. 25, no. 5-6, pp. 354-361, 1993.

[16] A. M. Donald, "The use of environmental scanning electron microscopy for imaging wet and insulating materials," Nature Materials, vol. 2, no. 8, pp. 511-516, 2003.

[17] M. Mazumder, R. Ahmed, A. Wajahat Ali, and S.-J. Lee, "SEM and ESEM techniques used for analysis of asphalt binder and mixture: a state of the art review," Construction and Building Materials, vol. 186, pp. 313-329, 2018.

[18] C. Kittel, Introduction to Solid State Physics, vol. 8, Wiley, New York, NY, USA, 1976.
[19] C. Howlader, M. Hasan, A. Zakhidov, and M. Y. Chen, "Determining the refractive index and the dielectric constant of PPDT2FBT thin film using spectroscopic ellipsometry," Optical Materials, vol. 110, Article ID 110445, 2020.

[20] M. Mazumder, R. Ahmed, M. Hasan, S.-J. Lee, and M.-S. Lee, "Spectroscopic ellipsometry of asphalt binder: a study of optical constants," International Journal of Civil Engineering, vol. 18, no. 3, pp. 251-259, 2020.

[21] H. G. Tompkins and W. A. McGahan, Spectroscopic Ellipsometry and Reflectometry: A User's Guide, Wiley, Hoboken, NJ, USA, 1999.

[22] J. A. Woollam, B. D. Johs, C. M. Herzinger, J. N. Hilfiker, R. A. Synowicki, and C. L. Bungay, "Overview of variableangle spectroscopic ellipsometry (VASE): I. basic theory and typical applications," in Optical Metrology: A Critical Reviewvol. 10294, International Society for Optics and Photonics, Article ID 1029402, 1999.

[23] F. A. Jenkins and H. E. White, Fundamentals of Optics, Tata McGraw-Hill Education, New York, NY, USA, 1937.

[24] A. T. Pauli, R. W. Grimes, A. G. Beemer, T. F. Turner, and J. F. Branthaver, "Morphology of asphalts, asphalt fractions and model wax-doped asphalts studied by atomic force microscopy," International Journal of Pavement Engineering, vol. 12, no. 4, pp. 291-309, 2011.

[25] H. H. Kim, M. Mazumder, and S. J. Lee, "Micromorphology and rheology of warm binders depending on aging," Journal of Materials in Civil Engineering, vol. 29, no. 11, Article ID 04017226, 2017.

[26] H. H. Kim, M. Mazumder, A. Torres, S. J. Lee, and M. S. Lee, "Characterization of CRM binders with wax additives using an atomic force microscopy (AFM) and an optical microscopy," Advances in Civil Engineering Materials, vol. 6, no. 1, pp. 504-525, 2017.

[27] S. J. Rozeveld, E. E. Shin, A. Bhurke, L. France, and L. T. Drzal, "Network morphology of straight and polymer modified asphalt cements," Microscopy Research and Technique, vol. 38, no. 5, pp. 529-543, 1997. 